\title{
The Mystery of Freedom and Neurolaw
}

\author{
Adrian Sgarbi \\ Pontifícia Universidade Católica do Rio de Janeiro, Universitat de Girona, Girona, Spain \\ Email: asgarbi@puc-rio.br
}

Received 5 March 2015; accepted 6 June 2015; published 10 June 2015

Copyright (C) 2015 by author and Scientific Research Publishing Inc. This work is licensed under the Creative Commons Attribution International License (CC BY). http://creativecommons.org/licenses/by/4.0/

c) (i) Open Access

\section{Abstract}

In the case of Steward Mach. Co. v. Davis, Judge Benjamin Nathan Cardozo said that "Till now the law has been guided by a robust common sense which assumes the freedom of the will as a working hypothesis in the solution of its problems". This hypothesis, which has previously been defended almost wholly within the confines of philosophical reflections on human responsibility, now seems to be undergoing a new wave of considerations. This is because neuroscience has been brought to bear in court proceedings in order to challenge the existence of human free will, in cases of both civil and criminal law. In the media, to a greater or lesser degree, various specialists have published the results of all kinds of experiments along with diagrams and graphs, technical advice and new machines to back up their claims. Currently, the use of some of these techniques in court and their lack of sustainability in many situations has, in turn, been emphasized, especially in the context of judicial proof (and reasonable doubt). In this sense, we can say that the issue of free will has been considered, but not always clearly, on three different levels: as a problem of description, of substance or of prescription. At the descriptive level is the question of what exactly we mean when we talk about free will. On the substantive level is the question of whether or not human beings actually possess this quality called free will. And finally, on the prescriptive level is the question of what we do with this knowledge. In this article, we offer an analysis of the problematic relationships between these three levels, beginning with a critical look at certain descriptive positions. In the end, it is suggested that these isolated descriptions, whether in the field of neuroscience, or philosophy, have led to an impasse whose effect is that the assertion that freedom in human behaviour is an illusion, and free will, a great mystery. As a possible way out, we present three modifications to the debate in order to extend its intelligibility beyond the boundaries of the legal profession.

\section{Keywords}

Norms, Neurolaw, Compatibilism, Determinism 


\section{Introduction}

In the case of Steward Mach. Co. v. Davis, Judge Benjamin Nathan Cardozo said that "Till now the law has been guided by a robust common sense which assumes the freedom of the will as a working hypothesis in the solution of its problems” (US Supreme Court, Chas. C. Steward Mach. C. v. Davis, 301 US 548 (1937)). This hypothesis, which has previously been defended almost wholly within the confines of philosophical reflections on human responsibility (Hart, 1958; Ross, 1975; Nino, 1980), now seems to be undergoing a new wave of considerations. This is because neuroscience has been brought to bear in court proceedings in order to challenge the existence of human free will, in cases of both civil and criminal law (See Section 5 of this study and also: Entertainment Software Ass'n. v. Blagojevich, 404 F. Supp. 2d 1051 (N.D. Ill. 2005) (case: “violent video games”); Fini v. General Motors Corp, No. 227592, 2003 Mich. App. LEXIS 884 (Mich. Ct. App. Apr. 8 2003) (Case: "Brain damage due to an accident and subsequent compensation”); People v. Weinstein, 591 N.Y.S.2d 715 (N.Y. Sup. Ct. 1992) (Case: "brain damage and violent act”); People v. Goldstein, 786 N.Y.S.2d 428 (N.Y. Sup. Ct. 2004) (Case: “mental illness in an agent who pushed a woman onto subway train track causing her death”). In the media (Kershaw, 2002; Anon, 2002, “The Future of Mind Control” in The Economist; Gazzaniga \& Steven, 2005; Liptak, 2005; Lane, 2005; Overbye, 2007; Rosen, 2007; Saul, 2006; Hotz, 2009; Liptak, 2010; Eagleman, 2011), to a greater or lesser degree, various specialists have published the results of all kinds of experiments along with diagrams and graphs, technical advice and new machines to back up their claims (fMRI o funcional MRI (Functional Magnetic Resonance Imaging), for example, has been used in appeals in cases involving the death penalty. Goodenough \& Prehn, 2004; Chorvat, McCabe, 2004; Sinnot-Armstrong et al., 2008). Currently, the use of some of these techniques in court and their lack of sustainability in many situations has, in turn, been emphasized, especially in the context of judicial proof (and reasonable doubt) (Schauer, 2010).

In this sense, we can say that the issue of free will has been considered, but not always clearly, on three different levels: as a problem of description, of substance or of prescription. At the descriptive level is the question of what exactly we mean when we talk about free will. On the substantive level is the question of whether or not human beings actually possess this quality called free will. And finally, on the prescriptive level is the question of what we do with this knowledge.

In this article, we offer an analysis of the problematic relationships between these three levels, beginning with a critical look at certain descriptive positions. In the end, it is suggested that these isolated descriptions, whether in the field of neuroscience, or philosophy, have led to an impasse whose effect is that the assertion that freedom in human behaviour is an illusion, and free will, a great mystery. As a possible way out, we present three modifications to the debate in order to extend its intelligibility beyond the boundaries of the legal profession.

\section{Two Theories Accounting for the Issues of Freedom and Determinism}

When I turn on my computer, each component of it plays a role. It contains many components and each performs a particular task. In the event that any of these components is not working perfectly, my computer will not do what I expect of it when I run a program. Thus, when I turn on my computer and get no response, it is soon apparent that this frustrating situation is unavoidable due to the deficient physical condition of the machine.

The term "determinism" refers to the thesis that every event is caused by previous events, while assuming that all such events are governed by the laws of nature (Weatherford, 2005). It is also said that an event is causally governed by previous events, as well as by the laws of nature, when these events cannot fail to occur without violating physical laws or without different previous events having occurred.

However, despite this being a relatively simple concept, the notion of causality has been expanded in recent years with the aim of including phenomena related to the actual physiological make up of human beings and their psychological causes. This is because contemporary science recognizes the existence of factors that are intrinsic to the human mind, to genetic heredity and also to the environment. Such factors can influence how human beings respond (Sober, 2004: 67-74; Nino, 1980: 367-368). More intensive investigation into these statements has led to the emergence of two hypotheses: 1) “remote causation” and 2) "inevitability.” (Sober, 2004: 67-74; Nino, 1980: 367-368).

1) According to the hypothesis of "remote causation", the action of agents is merely a reflection of genetic conditions (genetic determinism). Therefore, it holds that human actions are as free as the action of a computer that meets its factory specifications, i.e., human actions derive from biological programming which may or may not have defects and which are predictable (Sober, 2004: 73-74). 
2) According to the hypothesis of "inevitability", human beings are seen as merely reactive beings in terms of their psychological abilities (psychological determinism). Thus, kleptomaniacs react according to their peculiar situation, which drives them to steal. Those who suffer from an intrusive psychological compulsion repeatedly perform the same act; an abused child can become a dangerous individual upon reaching adulthood and in none of these cases does it make much sense to consider their reactions as free, since they simply do what they are able to do (Sober, 2004: 74; Ferraz Júnior, 1980, 99-105).

It is easy to see that the notion of determinism seems to put in doubt the idea of human freedom and, taken to its logical conclusion, it questions whether rules are of any use at all. Because if humans are part of the natural world, if all phenomena necessarily occur, how can there be any scope for free action? Are human beings slaves to determinism? Does this mean that there is no freedom, nor any possibility of it?

These questions are far from new, but they continue to provoke bewilderment, derived principally from the notion that humans cannot be free (Caro, 1998: 167-195).

These are the two propositions in the debate:

(PD) Proposition of determinism: “All actions have causes that determine them";

(PF) Proposition of Freedom: "There are at least some actions which we take freely."

Based on these two propositions, there are two theories that have sought to answer the question of freedom: incompatibilism and compatibilism. The incompatibilists claim that the statement "All actions have causes that determine them" is irreconcilable with the statement "There are at least some actions which we take freely". Compatibilists argue that these statements are reconcilable and try to defend this thesis.

The basic premise of incompatibilism is that the statements, PD and PF, are irreconcilable, in such a way that they are mutually exclusive and jointly exhaustive. However, incompatibility theories do not consist of a single line of thought regarding the consequences of accepting that such compatibility is impossible (Kane, 1996; O’Connor, 2000). Hence the difference between:

a) "radical" incompatibility theory (hard determinism), and

b) "liberal” incompatibility theory (libertarianism).

For the hard determinists a), acceptance of the first proposition means that we lack any freedom whatsoever. They are called "hard determinists" because, although it is hard to accept, the truth is that freedom is an illusion resulting from an erroneous and subjective human projection. People do not, in fact, have free will because their decisions are determined. This means that:

If $P D$, then not- $P F$

$P D$

Therefore, not- $P F$

But for the libertarian b), it is the second statement, PF, which is true. In these terms:

If $P D$, then not- $P F$

$P F$

Therefore, not- $P D$

The central thesis of libertarian incompatibilism is that freedom is only possible in an undetermined world (Wolf, 1981). Libertarians believe that this undetermined environment is to be found in some part of our brain that makes volition and self-forming actions (SFA's) (Kane, 2007, 14 ff.) possible. Such volitions and selfforming actions are what constitute our character and motives, making us who we are (Nichols, 2004).

These contrasts aside, what matters is that both of the incompatibilist formulations agree with the assertion that PD and PF are irreconcilable, since all incompatibilists defend the thesis that coexistence between freedom and determinism is impossible. The hard incompatibilists use this incompatibility to negate freedom. The libertarians use it to negate determinism in our own decisions.

The problem is that if freedom and determinism appear to be incompatible, the same can be said about the dichotomy of freedom and indeterminism. To say that the decisions made by our brain are consequences of undetermined events is the same as saying that our professed freedom and our objectives are based on a lack of control over our decisions and actions or that they consist of random effects, which would mean that our choices are selected, in the end, without any relation to objectives or opinions. In other words, "if a choice lacks cause it becomes an irrational act” (Moya, 1997: 59). In this sense, the proverb "The enemy of my enemy is my friend” is not true in all situations.

As is clear from the above, against incompatibilism, and as a way out for indeterminism, some have defended the thesis that determinism does not exclude the premise of freedom. This thesis is referred to as compatibilism. 
For compatibilism, although PD is true (i.e., although all actions are causally determined) nothing prevents us from being free, i.e., PF can also be true (Davidson, 1995: 85-106; Lewis, 1981: 113-121; Wolf, 1981). In other words, according to compatibilism, the determinist proposition and the freedom proposition are both true.

This means that determinism is true, but we can act freely; human actions are free and, at the same time, causally determined. For compatibilists, freedom does not require that causal determinism is not true. They argue this, in the final analysis, while noting that the clash between freedom and determinism is only apparent. To explain it, compatibilists say that we should investigate "what is meant by freedom." (Nino, 1980: 373-374). That is, they do not go as far as to deny the truth of the statement PD and the importance of understanding physical, psychological or genetic causality. The thing to highlight here is the modification of the second statement, PF. Proceeding thus, compatibilism not only denies incompatibility of PD and PF (in all its forms, from libertarianism or hard determinism) it also takes on the task of finding proof of what it claims.

\section{Concept of a Free Being}

Based on the above issues, as has been mentioned, the compatibilist strategy consists of a proposed reformulation of the statement of freedom to demonstrate the falsities of incompatibilism. Henceforth, I will this discuss this strategy using two conditions often put forward by compatibilists as "the conditions of freedom":

1) the condition of the agent's "self-determination" and

2) the condition of "alternatives" or "empirical possibilities of choice”.

\subsection{The Condition of the Agent's Self-Determination}

Every day we carry out a series of predictions about what will happen based on experience: putting a few teaspoons of sugar in coffee will sweeten it; impelling our legs forward will make us move; by drinking water we will slake our thirst, etc., the obvious implication of these experiences is to trust that something works or will work as it did in the past and we support this impression by the notion that we generally have about causality. Another example is the control over certain behaviours through reprimands, as well as praise directed at such behaviours as approved by the Law (Kelsen, 1957: 231; Bobbio, 1977: 33-42). We believe they have some usefulness because we attribute to them a certain degree of efficiency in terms of causing changes in the world.

In order to explain this, while safeguarding the idea of freedom, compatibilists sustain that autonomy (or an individual's capacity for self-determination) is required as the first condition for defining someone as free. Under this requirement, the agent acts freely only when their actions are not determined solely by factors beyond their control, whether they be genetic or physiological factors of some kind.

Thus, according to Harry Frankfurt, the question of self-determination is resolved by a hierarchy of control. It is a compatibilist construction because, as he understands it, his theory enables us to identify a component of free will that makes sense in the face of determinism (Frankfurt, 1971: 9-10).

The difference between humans and other mammals (Frankfurt calls them "lower mammals") is that human beings are capable of having desires about desires (or meta-preferences) (Bayon, 1991). Frankfurt called such complex mental states "second-order desires." Let us suppose, for example, that I want to eat a potato omelette every day. This is my first-order desire. While this is true, I would also like not to have the desire to eat potato omelette every day because I'm getting fat by eating them every day. The second-order desire can be worded as "I wish I did not want to eat potato omelette, or so many potato omelettes, every day."

According to Frankfurt, animals that are less sophisticated than humans may have first-order desires, but not second-order desires. A dog may want to eat meat and is therefore capable of feeling first order desires. However, the dog cannot wish not to eat meat every day. A dog is incapable of having second-order desires or of considering the initial desire and then negating it, if that is the case (Frankfurt, 1971: 10-11).

There are various types of second-order desires (Frankfurt, 1971: 17-18).

The first consists of not wanting to have the desire that was felt initially, as in our example of the potato omelette.

The second is a desire to acquire a desire you do not feel. For example, it may be that I have no desire to eat healthy food every day, but I would like to have this desire.

The third type is what occurs when one or more first-order desires are in conflict with another first-order desire. I want to lose weight but, at the same time, I want to eat potato omelette. The second-order desire in this scenario is that I want the desire to lose weight to overcome the desire to eat potato omelettes every day because 
I understand the desire to eat tortillas every day is a bad desire due to the fact that I want to lose weight.

According to Frankfurt, human beings are able to think about their desires and reflect on what they would like to continue desiring or not. He believes that this is because they are beings who act according to reasons or motives. Therefore, provided that human beings act according to their second-order desires, they are acting freely. In this sense, drug addicts, mentally disturbed agents or even individuals who compulsively scrub their hands till they are raw, are not free because they do not have the capacity for second-order desires. Although a drug addict may have the desire to not want to use drugs, until this desire prevails, they will not be free. In short, according to Frankfurt, freedom consists of volition that is effective in producing behaviour, so that when an agent manifests effectively the volition he desires, the will as he wants it to be, then he has free will, then he is free (Frankfurt, 1971: 20).

Thus, in Frankfurt's view, young children, people with mental problems, or even people with compulsions (such as kleptomania) are not autonomous and, as such, are not free, because although they may have first-order desires, they are unable to have meta-preferences or effective second order desires. These agents live in a world without the capacity for self-reflection and, therefore, only have certain desires.

\subsection{The Condition of "Alternatives" or "Empirical Possibilities of Choice"}

Even if we accept the compatibilist approach described in the previous section, this only, strictly speaking, explains free action in the sense of the "freedom to decide." And this freedom is recognized or not from a negative viewpoint: if there is any interference which, by itself, is the cause of the decision, the agent will not be free. Meanwhile, the absence of constraints is insufficient to prove that the agent is acting freely; and it is insufficient because the agent in question may well not find "conditions in which to do what he chooses to do" (the condition of "alternatives"). That is, up to this point, we have dealt with "freedom of choice" but not "freedom of action." Therefore, nothing has been said with regard to the problem of the causal efficacy of the manifested intention (O’Connor, 1993a, 49-52).

"Freedom of action" can be taken to mean the ability to do what you want to do. In other words, to have freedom of action means to put preferences and meta-preferences into action (O’Connor, 1993b).

Two examples may serve to illustrate the difference between "freedom of choice" and "freedom of action."

1) Freedom of choice, but not freedom of action: an obvious example of this is the situation of the lazy man and his faulty car. Imagine that John Doe goes out to buy bread in his car and that the bakery where he buys the bread is in the same block in which he lives so that, to get to the bakery all he needs to do is start his car and always turn to the right. Imagine now that John Doe's car has a serious fault in the steering column and, in fact, can only turn right. And imagine also that John Doe always turned right at all times as he drove his car, even though there existed the condition for him to decide to turn to the left.

2) The freedom of action, but not the freedom of choice: the condition in which there is freedom of action but not freedom of choice can be imagined by reflecting on the situation of a somnambulist (Saul, 2006). Who is sleepwalking from one place to another. Although he is engaged in movement, it is not strictly voluntary.

In this sense, "free action" seems to depend on two factors:

a) That there are no impediments or obstacles that prevent the agent from doing what he wants to do.

b) That the agent can decide whether to do or not to do something, in response to his own free will—which is uncontaminated by factors that may impede the agent's physical action.

The conclusion, therefore, is that "freedom" depends on the absence of "impositions that interfere with the decision" and "impositions that interfere with the action" (Kahane, 1983: 245-373). According to this notion, to consider a concept of freedom without choice is to consider something "without sense" and to consider a concept of freedom without action is to consider something which is "empty".

\section{The Mystery of Freedom}

The incompatibilists have put forward certain objections with regard to the "conditions of freedom" discussed in the previous section. Such objections have served as a basis for some authors to talk about a "mystery of freedom”, a mystery that has often generated sceptical attitudes with regard to this issue.

\subsection{First Objection}

By way of a first specific objection, it has been claimed that, even if one accepts the condition of self-determi- 
nation as a condition for someone to be free, this condition says very little in the sense that we can always insist that, although "free" decisions conform to the "condition of self-determination" they are determined by cerebral inputs "in the agent" that operate according to the chemical-physical reactions that occur as the agent deliberates.

In this context, the thesis of "psychological determinism" and "genetic determinism" become problematic because according to the theory of psychological determinism, our behaviour is, in one way or another, psychologically compulsive and, according to the theory of genetic determinism, we do what our genetic construction allows us to do. That is, we can say that this "relevant will” is entirely determined. In other words, there can be no actual "free will". This would mean that the will is not only determined in pathological situations, but also in "normal” situations.

Moreover, as we discussed previously, if Frankfurt's proposal is that people act freely when second-order desires are specifically linked to first-order desires, this means that true freedom consists of whether the agent can alter first order desires by reflecting on those desires. The problem with this formulation-according to the incompatibilists-is that you can also ask why, in his "meta-preference", is the agent is free?

Given this insistence, what appears to become the most likely way forward is to conclude that thinking about freedom is simply a waste of time or at least it is an activity which, being doomed to failure, has very few advantages (when we deal with it).

Thomas Nagel, for example, assumes this position. For Nagel, "This is not a case where there are several possible candidate solutions and we don't know which is correct. It is a case where nothing believable has (to my knowledge) been proposed by anyone in the extensive public discussion of the subject.” (Nagel, 1986: 112).

Furthermore, Nagel is not alone in thinking this. Peter Van Inwagen has offered a well-known defence of this idea according to which "free will remains a mystery" (Inwagen, 1983: 174). He goes on to say that "Indeed the problem seems to me to be so evidently impossible of solution that I find very attractive a suggestion that has been made by Noam Chomsky (...) that there is something about our biology, something about the ways of thinking that are "hardwired" into our brains, that renders it impossible for us human beings to dispel the mystery of metaphysical freedom.” (Chomsky, 1975: 15; Inwagen, 1983: 174-175). In support of his conclusions, Van Inwagen also includes references to the ideas of Colin McGinn who, like Chomsky, pointed out that "free will is a mystery, and therein lies its possibility.” (McGinn, 1999: 168). That is to say, the reasoning on which these positions are based is the consideration of an internal or mental blueprint for decisions.

In this way, the McGinn formulation is relatively simple. For McGinn, when an agent wants to eat something and sees an apple on the table, he picks it up in order to eat it. This is a typical example of mental causation. However, in this decision or rather, during the course of this mental causation, is there any space for freedom? According to McGinn, there is not. Thus, neither the libertarian incompatibilists nor the compatibilists would have resolved the issue satisfactorily: all these constructions fail if we take into account that mental causationwhich is, according to McGinn, the real place for discussing freedom-cannot be reduced to physical causation and, therefore, cannot be treated as an externally caused constraint. Thus, again according to McGinn, an explanatory model of mental causation that aims to be sufficient to explain non-compulsive actions should address the problem of the control an agent has over his own actions and the possibility of deciding otherwise in the light of the options he is presented with (McGinn, 1999: 167-168).

\subsection{Second Objection}

The second specific objection is that it can be said that the condition of alternative possibilities to choose from is questionable. In this context, we can use Locke's analogy of the "closed room”.

Locke, in section 10 of his Essay Concerning Human Understanding, Book II, Chapter XXI, Of Power, asks if we can doubt the freedom of an agent who, while fast asleep, is carried into a room in which there is a person he wanted very much to see (Locke, 1690). Locke questions whether the agent can be considered free if we assume that, upon waking up and seeing this person he becomes so happy that he resolves to stay in the room to be with this person without knowing that the door of the room is locked from the outside. Locke's answer is that the agent is still free, although the locked door is a real obstacle to any alternative option. According to Locke, given that the agent's decision would have been to stay, it does not matter much whether he is unaware that this is his only option because there is only a limit to freedom if the "power of doing" is nullified, which is not the case in this situation. 
We know that causal determinism requires a certain understanding of "how" some things happen in the physical world, i.e., we begin from the understanding that the physical world is causally determined by preceding events and successive events are conditioned by the preceding events. Thus, the human body is subject to this elementary fact: when I move my leg forward, this movement is determined by physical causes that enable such movement, some of which I may not even be aware of. But if this is correct in all situations, there is something odd about it. For example, when I am hungry, my impulse is to get some food. But at the same time, I can deny this urge and remain hungry, when, for example, I go by a greengrocer's and do not take any food to resolve the problem of my hunger, because I know that this would be stealing. Thus, it is true that there is some aspect which is physical and determined (the movement of my legs and my arms when walking), but there is also something that, at least, we believe escapes the laws of the physical world, i.e. (as in the example), the fact that I refuse to steal. Rather, the perception is exactly that which makes the symbolism of the "hunger strike" so expressive: deciding, in every moment, not to eat, even though this will do harm to my body and, in the end, that this attitude may kill me.

What we have, therefore, is the perception that if the mental were reduced only to the physical, I would be completely determined by physical causality and therefore could not act in any way other than in accordance to the physical causal relationships involved. And that this idea would be problematic in the sense that we are aware that there are parts of our physical body which seem to depend on our decisions (when walking, for example) and others that are independent of them (the functioning of my kidneys). But if I begin with the notion that the mind and the body are separate, as seems inevitable in order to make the statement "I am free to do what I want" true or plausible, then I must concede that the mental is governed by its own laws, and this means that not all of my body is causally determined. The problem is that, if this is true, I am assuming two explanations as being correct, despite the fact that they are mutually exclusive in explaining the same phenomenon: my action (or human action in general) is governed by two series of causal phenomena, one physical and one mental, as if there was a "disembodied mind". And this sums up the "mystery of freedom": the mental choice is not a solution if it is the case that I am conditioned to it in the same way as I am in my physical life. But if my life is not governed by mental causation, what is it governed by?

\section{Just an Illusion}

With all these evident obstacles, the real question remains: what is the solution to the problem of freedom? Because if, on the one hand, understanding freedom in its final relationship with mental impulses seems to lead to a dead end, on the other hand, admitting that we are not free seems to result in accepting that there is no individual responsibility and that rules are inefficient as instruments of social control.

Faced with this situation, some authors have used the word "illusion" and propose that there is a "social function for the illusion of freedom” or "for accepting that we are free without further inquiries."

Thus, Thus Saul Smilansky says that "illusionism is the position that illusion often has a large and positive role to play in the issue of free will. This illusion is reinforced by the actual role it plays and, since it is very important in terms of social organization, it must be maintained (Smilansky, 2000: 169-170). This is because by believing, in basic terms, in the illusion of free will, people perform actions and feel them to be their own and consequently they can feel remorse (Smilansky, 2001: 88-94).

Humanity, says Smilansky, "fortunately deceived on the free will issue, and this seems to be a condition of civilized morality and personal value”. He goes on to say that the illusion of free will consists, firstly, of the false conclusion that free will exists and, secondly, by the need to maintain this false perception of things (Smilansky, 2000: 170-171).

The illusion referred to by Smilansky serves a practical need: the need to repress, the need to learn and that, with this, we may be happy being governed by parameters that we ourselves establish socially. But this does not mean that this illusion equates the contaminated will with the uncontaminated will. Part of this illusion consists of the idea that, in situations where the agent acts while suffering some contamination of his will, he is less blameworthy than if such contamination does not exist. In this sense, in most cases, this illusion is positive, bearing in mind that the "illusion of freedom" allows there to be a collective perception (Smilansky, 2000: 204205).

In short, Smilansky finds necessity to be the answer to the problems posed in the debate between incompatibilists and compatibilists. For Smilansky, there are good psychological and philosophical reasons for illusion: 
illusion is the human condition.

\section{Exploring Other Avenues}

As we noted at the beginning, the assumption of free will is a working hypothesis in the legal context, at least the American one (Steward Machine Co. v. Davis, 301 US 548, 590 (1937). See also Bethea v. United States, 365 A. 2d 64, 83 n. 39 (DC 1976) (While the deterministic theory of behaviour "has some adherents, the notion that a person's conduct is a simple function of extrinsic forces and circumstances over which he has no control is an unacceptable contradiction of the concept of free will, which is the sine qua non of our criminal justice system”); Kwosek v. State, 100 NW2d 339, 345 (Wisc. 1960) (“A human being has inherently and within himself a free will—the power of self-control.”); see United States v. Grayson, 438 US 41, 52 (1978); Morissette v. United States, 342 US 246, 250 (1952); "The lawyers in all countries will answer 'if there is no reason, no choice, no will, then there can be no law'" [Berman, (1961) Law as an Instrument of Mental Health, 109 U.Pa.L.Rev. 361, 366] cited in Blocker v. United States, 288 F.2d 853, 867-868 (DC Cir. 1961); Steward Machine Co. v. Davis, 301 US 548, 590 (1937), see also Bethea v. United States, 365 A. 2d 64, 83 n. 39 (DC 1976), "For the protection of society, the law accepts the thesis that all men are invested with free will...” State v. Sikora, 210 A.2d 193, 202 (NJ 1965), "Our jurisprudence... ultimately rests on a premise of freedom of will. This is not to be viewed as an exercise in philosophic discourse, but as a governmental fusion of ethics and necessity, which takes into account that a system of rewards and punishments is itself part of the environment that influences and shapes human conduct.” United States v. Brawner, 471 F. 2d 969, 995 (D. C. Cir. 1972). I will now present three adjustments to the thinking on the issue of free will which we have described above. The three adjustments are, respectively:

- an adjustment of the description, aimed at solving the problem of the leap in logic;

- an adjustment of the substance, which addresses the issue of descriptive reduction and its relation to investigations into the possibility that free will exists; and

- an adjustment of the prescription, with which I will present the scope of the possible uses of work carried out in the field of neurolaw (Belcher and Sinnott-Armstrong, 2010).

\subsection{First Adjustment: The Adjustment of the Description}

As noted by von Wright, it is a mistake to equate determinism in the natural sciences with determinism in the social sciences. While the first is based on the universality of physical experiences, the second is tied to conventions and social pressures (Von Wright, 1976: 415). The two have different goals: in the natural sciences, we study the phenomena of the general laws of nature, while in the human sciences we study the social realm of institutions and their rules (Von Wright, 1976: 415).

As von Wright points out, this does not mean that there are no analogies or parallels between the natural and social sciences. Both sets of laws govern in their respective fields: social laws govern in a prescriptive sense in society while natural laws govern in a merely descriptive sense in nature (Von Wright, 1976: 415-416). However, the differences are significant: "In the natural sciences deterministic ideas are connected to other ideas, in which universal regularity, repeatability and experimental control are assumed. In the social sciences, immediate connections are limited to motivation and social pressure, to guidelines and intentions. In the natural sciences, determinism is broadly used to make predictions; in the human sciences, there is a greater emphasis on retrospective explanations.” (Von Wright, 1976: 416).

In these terms, deterministic ideas, taking into account the differences noted, are not the same in the two sciences. And these differences can in no way be ignored, even though many insist on the mystification of nature in an attempt to encompass humans in considerations into which they do not fit. And, it is this mistake that, according to von Wright, has limited the analysis of humans to internal causes when freedom must also be analyzed within social aspects, or rather, in terms of their will, their desires, their passions, their feelings and in their manifest deliberations. Thus, human freedom is better circumscribed when it is analysed according to the contextual aspect of institutional human relationships, and not as electro-chemical relationships

What has been observed since von Wright can now be explained, according to M. Schlick, with the term "category mistake", because Schlick, referring to the social laws and human laws, makes it clear that these do not belong to the same category of meaning, and he does so, first of all, by offering some precise observations on the meanings of "law." (Schlick, 1939: 146). 
Schlick emphasizes that, in practice, certain rules with respect to the behaviour of individuals have been prescribed by law. One of the most efficient ways to have such rules obeyed is to establish sanctions (penalties) which oblige agents to act in certain ways so as to avoid the consequences. However, in the natural sciences, laws are something else entirely. Scientific laws do not prescribe how we should act; they are formulas that describe how nature works (Kistler, 1999). In fact, the only thing they do have in common is that they are both expressed in formulas: social laws provide a formula for how we should behave while natural laws provide a formula for how nature operates. But apart from this, according to Schlick, there is nothing else to connect them. The laws of mechanics do not prescribe how the planets ought to move: Kepler's laws of planetary motion in no way interfere with the movement of the planets. And yet there is some confusion regarding events and natural necessity. It is said that both human events and physical events can compel individuals despite the fact that no will exists in nature (Schlick, 1939: 149).

This being so, Schlick declares that freedom is the opposite of compulsion: a man is free if he is not subject to a compulsion that prevents him from doing what he desires; a compulsion such as that caused by, for example, mental illness or, in other cases, drugs. However, nature does not prescribe; nature does not compel at all. And this is why the universal validity of the laws of natural science should never be confused with the application of the laws of the State; not even nature itself excludes freedom (Schlick, 1939: 146-147).

With this in mind, it seems the correct understanding of freedom is located somewhere in the realm of "absence of constraint" and, therefore, that we need to understand the meaning of "being compelled". Because "being compelled" implies a power relationship and nature does not make use of intentional relationship; nature does not exercise "power" over men, unless we take the word "power” in a way far removed from its intersubjective social implications.

\subsection{Second Adjustment: The Adjustment of the Substance}

The second adjustment is based on the study by John L. Austin in his essay, A Plea for Excuses, published in the Proceedings of the Aristotelian Society, 1956-1957. Austin's work focuses on the concept of “excuses" and the act of excusing oneself (Austin, 1955: 1-3.) and, as such, is crucial to understanding what may be called here the social function of the notion of freedom.

According to Austin when we make our excuses for something, we say that our actions did not turn out well or that we would have liked it to come out differently. Therefore, the word "excuses" is a rather general label that covers a family of notions, such as “justification”, “mitigation” “excuses”, “pretexts” “extenuation” “palliation" and so on. To all these nouns can be added the terms used to describe the actions. Taken together they serve to characterize human actions. And some of the terms that describe the actions are more common than others, such as "freely”, “clumsily”, “spontaneously”, “under obligation”, “deliberately” and so on. Austin understands that, in this sense, the study of excuses is a relevant part the examination of actions and this is the path towards the study of human freedom (Austin, 1955: 3).

Austin draws attention to the difference that exists between the act of “excusing” and "justifying”. Both are forms of defence in connection with an untoward action.

Suppose that an agent, $\mathrm{X}$, did something and "excuses himself” for doing so. $\mathrm{P}$, his lawyer admits that X performed the act for which he is being judged, but denies that there was a crime. In this case he is "justifying” the act performed by X. However, there is another more fragile line of argument. It can be said that, although X did in fact do what he is alleged to have done-and for this reason his act is blameworthy-he did not perform the act in a "pure" way: the fury that took control of him meant X was not in a condition to control himself. In this case, what we have is an "excuse". The question is that if X acted freely and it involves an act attributed to him as socially negative (a crime), then he deserves punishment, although less severe, considering the particular context of the case (Austin, 1955: 3-4).

The examples provided by Austin, mutatis mutandis, apply to the problem of freedom, because an agent is responsible (at least morally) for his actions when they are made freely. So, when can we use the adverb "freely"? This issue clarifies something missing in the perception of the problem of freedom explored in the previous sections: freedom is not an all-or-nothing concept. Therefore, in our search for the conditions of freedom, we must include the perception that the great clash between determinism and freedom is, to a large degree, a mistake, since the understanding of freedom, the substance of freedom, is limited to the characterization of certain actions, not all actions: we can only be free when it is possible to act freely. The excessive use of adverbs such as 
"freely", without the minimum of care, produces false problems.

In essence, what is at stake here is, on the one hand, the notion of "freedom in an ontological sense" and, secondly, the notion of "social freedom" and the possible relationships between the two (Strawson, 1962; Nino, 1987: 106-107; Nino, 1980: 374-380). While the ontological investigation places freedom in a timeless context and attempts to understand its possibilities in an abstract fashion, the idea behind social freedom (which may be political, moral, religious, legal, economic, etc.) is pragmatic and specific data is considered as operative, since the forms of social restrictions are multiple. That is, while the questions posed by ontological freedom concern the relationship between man and nature, social freedom focuses on the relationship between individuals and power (Pettit, 2001).

\subsection{Third Adjustment: The Adjustment of the Prescription}

The third adjustment is the adjustment of the prescription (i.e., what we do with this knowledge). To clarify this, we will once again turn to von Wright. According to the premise made in The Varieties of Goodness, in which the morality of an action performed by an individual is measured in terms of how it affects the welfare of his fellows, von Wright points out that human actions, although subject to determinants and restrictions, are concerned with human motivations and social pressures_and not causal determinations (Von Wright, 1963: 189190). Furthermore, there being no room for action, any thoughts on freedom would have little or no physical sense (Von Wright, 1984: 109-112).

In order to understand this point fully, it is important to note the difference that von Wright draws attention to between the field of determinism and the field of freedom (Von Wright, 1974: 113-114).

According to von Wright, the field of determinism is the natural world and natural sciences are used to study it. In contrast, the field of freedom is the human and social world and it is studied using the social sciences. Hence, the distinction between physical nature, on the one hand, and intentionality, on the other. Although causality (part of the physical world) and freedom (part of the social world) do in fact intersect, they are nevertheless different categories.

In other words, for von Wright, human actions are ascribed to reasons, and as such, are not predetermined. In this sense, a message from my brain to my body does not cause (except in a purely metaphorical sense) an action, but rather, it activates the agent's desire to carry it out. The path this message takes is purely mental/chemical; there is no cognitive or informational component to it.

This being so, von Wright associates the notion of freedom with human capabilities. And, in this case, saying that someone acted freely in the world is the same as determining that he, the agent could have acted otherwise. But what do we mean by acting otherwise?

According to von Wright, three different things can be understood by the possibility of acting otherwise:

1) that the action, from a logical point of view, is a contingent action, that is, to describe an omission is not a contradiction;

2) that the agent had the ability to do (or refrain from doing) the action in question; and

3) the agent acted as he wanted because he acted for a reason.

It should be noted that, while the first point is formal, the second is empirical because it expresses the potentiality of actions that were in fact not carried out (but were all possible). Finally, the third point expresses the agent's self-determination. Therefore, "logical possibilities”, “capabilities” and "reason” are the building blocks of freedom in von Wright's view.

The sum of all this is that if the agent had some other reason, he would have acted otherwise. Therefore, the more reasons an agent has, the freer he will be, because his freedom expands in proportion to the choices there are by reason of the possibilities he visualizes with those reasons (Moya, 1997: 64). In other words, the more decision-making capacity the agent has, the freer he will be, and hence the dependence on training, education and so on.

Thus, von Wright's ideally rational agent is one whose reasons for action are always anchored in ultimate ends. This is von Wright's "range of freedom", which is firmly linked to the concrete reality of individuals. That is why the idea of human freedom is not the same for all societies and cultures, since it is nonsense to think of some kind of "core of freedom" (an ontology) that will be revealed. Greek freedom is not the same as socialist freedom, nor is it the same as freedom in a fundamentalist country or a liberal democratic country. The aspirations, abilities and reasons that each agent has in these various places and eras are not the same. There is no no- 
tion of freedom that escapes history and culture.

Von Wright, in his understanding of freedom as the ability to make or do different things, categorizes freedom into potential freedom and actual freedom (Von Wright, 1984: 116):

1) Potential freedom is this generic capability;

2) Actual freedom is the agent's ability to perform or omit certain actions.

Thus, actual freedom depends on the number of restrictions that affect potential freedom. Von Wright classifies such restrictions as "external” and "internal".

a) External restrictions consist of physical restrictions that prevent or make it impossible for someone to do something and normative restrictions of a legal or moral nature instituted in the agent's social order, or orders (Von Wright, 1984: 117).

b) Internal restrictions are also subdivided into psychological and normative.

The psychological restrictions include "mental forces" ranging from desire and temptation to fear and hatred; the normative restrictions consist of the rules internalized by the agent and which govern their lives. Both internal and external restrictions may be powerful enough to prevent us from considering an agent to be free and responsible.

Thus, von Wright's conclusion is that in order to consider an action to be a free action, or an agent to have acted freely, the action must abide by the agent's reasons, even though it is potentially limited. This theoretical position, which consists of understanding the institutional limitations of human action and its consequences in relation to its institutions, is what allows freedom to be analyzed as an action that is controllable by individual human deliberations and governed by socially established rules. As such, these rules are contingent and, therefore, variable among different societies. These external stimuli von Wright refers to as "normative pressure" (Von Wright, 1976: 419).

The consequences of this normative pressure vary according to the institutional rule concerned, i.e., in terms of its moral or legal nature. But, in any case, what matters is that this external determinant is, little by little, assimilated by the recipients of the rules, and thus becomes an internal determinant. This gradually reduces the need for external intervention. Von Wright calls this transformation of external determinations to internal ones internalization (Von Wright, 1976: 419-420).

Hence, what von Wright is saying is that, given the multiple uses of the word "freedom", confusion has arisen concerning the relationship between individuals and nature on the one hand and, on the other, between individuals and society; a relationship that is established between individuals and power, or in other words, the individual and authority. This is because while the laws of the state are deontic modalities (establishing what is obligatory, permitted, forbidden), the laws of physics are alethic modalities (expressing what is possible, impossible and necessary) (Kiefer, 1994). In this way, von Wright not only solves the problem of causal determinism, but also that of social indeterminism: human actions are subject to reasons and socially constructed restrictions.

And it is with these arguments that von Wright defends the thesis which we shall call the von Wright thesis: “The concepts used for describing and explaining a man's actions, such as motive, reason, intention, choice, deliberation, etc., are all of them tied to the idea of 'freedom'. To deny that an agent is free is to commit a contradiction in terms. The 'mystery' of freedom, if there is one, is the 'mystery' of the fact that there are agents and actions.” (Von Wright, 1951: 78-79).

\section{Conclusion}

There are a number of particular conclusions we can draw from all of this.

1) The idea that the concept of freedom is under threat by neuroscience is the result of reducing the description of human actions to brain mechanisms and fatalism. The problem here is that, by explaining how the brain works, we are barking up the wrong tree. Because, since we are biological agents it will always be possible to identify some such mechanism, for example, cerebral, that is involved in our actions. In other words, the brain can function using automatic mechanisms, but the "freedom" that matters is found in social interaction.

2) It can be said that the normative pressure described by von Wright is a decisive factor in the formation of the second-order desires described by Harry Frankfurt. In this sense, Frankfurt's second-order desire is an "educated desire" (given the legal context in which it occurs), a desire held by an agent who is capable of reflecting on his initial impulses and of determining his behaviour using this capacity for reflection.

3) When Frankfurt's second-order desires are placed in a normative context, they take on the role of rule- 
based reasons. Because if, as Frankfurt believes, it is an agent's ability to reflect on his desires which makes him free (i.e., the capacity to have second-order desires), then in the social world of freedom, as described by von Wright, it is the ability that the agent has, or does not have, to decide within the terms of social rules that makes an agent free.

4) The question of Locke's locked room is not a problem when understood in the context of the normative field of law. This is because what is or is not an action-or possible alternative actions - is also regulated by rules and exceptions to these rules. In other words, the issue of alternative possibilities of (or alternative conditions for) choice are rendered by law into the possibilities of acting or not acting that are subject to institutional restrictions or expansion.

5) By saying that one of the conditions of freedom is the capacity to act according to reasons does not mean that an agent always acts rationally. The condition of being able to reflect on first-order desires does not require the agent to always act sensibly — in the evaluation of his peers. It simply requires that the conditions exist for the agent to reflect and evaluate his own actions.

6) In the light of all this and bearing in mind that reasons - and the capacity to act according to reasons-play a crucial role in Law, the current research field of neurolaw is relevant to the extent that it can present us with studies that indicate when the capacity to act according to reasons is in some way affected, or even suppressed. Such research includes studies into the impact of emotions and their intensity on behaviour which may or may not make it possible to justify mitigation or aggravation of punitive measures; studies into the stages of brain development and acts of violence and their relation to punishment and even studies that assess the capacity of discrimination for the purpose of civil acts. These are just some of the possible and, indeed, desirable areas of collaboration.

\section{References}

Anon (2002). The Future of Mind Control. People Already Worry about Genetics. They Should Worry about Brain Science Too. The Economist, 23 May 2002.

Austin, J. L. (1955). A Plea for Excuses. Proceedings of the Aristotelian Society, 57, 1-30.

Bayon, J. C. (1991). La normatividad del derecho: Deber jurídico y razones para la acción (The Normativity of Law: Legal Duty and Reasons for Action). Madrid: Centro de Estudios Constitucionales.

Belcher, A., \& Sinnott-Armstrong, W. (2010). Neurolaw. Wiley Interdisciplinary Reviews: Cognitive Science, 1, 18-22. http://dx.doi.org/10.1002/wcs.8

Bobbio, N. (1977). Le sanzioni Positive. Milan: Comunità.

Caro, M. D. (1998). Determinismo e libero arbitrio: Rinascita di una controversia. In M. D. Caro (Ed.), Caso, Necessità, Libertà (pp. 167-195). Napoles: CIEN.

Chomsky, N. (1975). Reflections on Language. New York: Pantheon Books.

Chorvat, T., \& McCabe, K. (2004). The Law and the Brain. Philosophical Transactions of the Royal Society B, 359, 17271736. http://dx.doi.org/10.1098/rstb.2004.1545

Davidson, D. (1995). Libertad Para Actuar. In D. Davidson (Ed.), Ensayos sobre Acciones y Sucesos (pp. 85-106). México: Crítica [English Version: Davidson, D. (1973) Freedom to Act. In D. Davidson (Ed.), Essays on Actions and Events (pp. 21-42). Oxford: Oxford University Press (First published 1980).]

Eagleman, D. (2011). The Brain on Trial. The Atlantic Magazine. July/August.

Frankfurt, H. G. (1971). Freedom of the Will and the Concept of a Person. The Journal of Philosophy, 68, 5-20. http://dx.doi.org/10.2307/2024717

Gazzaniga, M. S., \& Steven, M. S. (2005). Neuroscience and the Law. Scientific American Mind, 16, 42-49. http://dx.doi.org/10.1038/scientificamericanmind0405-42

Goodenough, O. R., \& Prehn, K. (2004). A Neuroscientific Approach to Normative Judgment in Law and Justice. Philosophical Transactions of the Royal Society B: Biological Sciences, 359, 1709-1726. http://dx.doi.org/10.1098/rstb.2004.1552

Hart, H. L. A. (1958). Legal Responsibility and Excuses. In S. Hook (Ed.), Determinism and Freedom in the Age of Modern Science (pp. 80-93). New York: New York University Press.

Hotz, R. L. (2009). The Brain, Your Honor, Will Take the Witness Stand. The Wall Street Journal.

Inwagen, P. V. (1983). An Essay on Free Will. Oxford: Oxford University Press. 
Kahane, H. (1983). Thinking about Basic Beliefs. Belmont: Wadsworth Publishing Company.

Kane, R. (1996). The Significance of Free Will. New York: Oxford University Press.

Kane, R. (2007). Libertarianism. In J. M. Fischer, R. Kane, D. Pereboom, \& M. Vargas (Eds.), Four Views on Free Will (pp. 5-43). Malden: Blackwell.

Kelsen, H. (1957). The Law as a Specific Social Technique. In H. Kelsen (Ed.), What Is Justice? Justice, Law, and Politics in the Mirror of Science; Collected Essays (pp. 231-256). Berkeley: University of California Press.

Kershaw, S. (2002). The Hunt for a Sniper: The Dead. Escaping the Grip of Cancer, Only to Die at a Sniper’s Hand. The New York Time, 16 October 2002.

Kiefer, F. (1994). Modality. In R. E. Asher (Ed.), The Encyclopedia of Language and Linguistics (pp. 2515-2520). Oxford: Pergamon Press.

Kistler, M. (1999). Causation and Laws of Nature. New York: Routledge.

Lane, C. (2005). 5-4 Supreme Court Abolishes Juvenile Executions. The Washington Post, 2 March 2005.

Lewis, D. (1981). Are We Free to Break the Laws? Theoria, 47, 113-121. http://dx.doi.org/10.1111/j.1755-2567.1981.tb00473.x

Liptak, A. (2005). Supreme Court Rule on Executing Young Killers. The New York Times, 4 January 2005.

Liptak, A. (2010). Justices Limit Life Sentences for Juveniles. New York Times, 17 May 2010.

Locke, J. (1690). An Essay Concerning Human Understanding. E-Book.

McGinn, C. (1999). The Mysterious Flame. New York: Basic Books.

Moya, C. J. (1997). Libertad, responsabilidad y razones morales. Isegoría, 17, 59-71.

Nagel, T. (1986). The View from Nowhere. Oxford: Oxford University Press. (Spanish Transl. (1996) Una visión de ningún lugar. Mexico: Fondo de Cultura Económica.)

Nichols, S. (2004). The Folk Psychology of Free Will: Fits and Starts. Mind \& Language, 19, 473-502. http://dx.doi.org/10.1111/j.0268-1064.2004.00269.x

Nino, C. S. (1980). Los límites de la responsabilidad penal: Una teoría liberal del delito. Buenos Aires: ASTREA.

Nino, C. S. (1987). Introducción a la filosofía de la acción humana. Buenos Aires: Universitaria de Buenos Aires.

O’Connor, T. (1993). Alternative Possibilities and Responsibility. Southern Journal of Philosophy, 31, 345-372. http://dx.doi.org/10.1111/j.2041-6962.1993.tb01726.x

O’Connor, T. (1993). Indeterminism and Free Agency: Three Recent Views. Philosophy and Phenomenological Research, 53, 499-526. http://dx.doi.org/10.2307/2108078

O’Connor, T. (2000). Persons and Causes: The Metaphysics of Free Will. New York: Oxford University Press.

Overbye, D. (2007). Free Will: Now You Have It, Now You Don’t. The New York Times, 2 January 2007.

Pettit, P. (2001). A Theory of Freedom: From the Psychology to the Politics Agency. Cambridge: Polity Press.

Rosen, J. (2007). The Brain on the Stand: How Neuroscience Is Transforming the Legal System. The New York Times Magazine, 11 March 2007.

Ross, A. (1975). On Guilt, Responsibility and Punishment. Los Angeles, CA: University of California Press.

Saul, S. (2006). The Ambien Case-Some Sleeping Pill Users Range Far Beyond Bed. The New York Times, 8 March 2006.

Schauer, F. (2010). Can Bad Science Be Good Evidence? Cornell Law Review, 95, 1191-1219.

Schlick, M. (1939). Problems of Ethics. New York: Prentice-Hall.

Sinnot-Armstrong, W., Roskies, A., Brown, T., \& Murphy, E. (2008). Brain Images as Legal Evidence. Episteme, October 2008 Issue.

Smilansky, S. (2000). Free Will and Illusion. Oxford: Oxford University Press.

Smilansky, S. (2001). Free Will: From Nature to Illusion. Proceedings of the Aristotelian Society, 101, 71-95. http://dx.doi.org/10.1111/j.0066-7372.2003.00022.x

Sober, E. (2004). Core Questions in Philosophy: A Text with Readings. New York: Prentice Hall.

Strawson, P. F. (1962). Freedom and Resentment. In G. Watson (Ed.), Free Will (pp. 187-211). Oxford: Oxford University Press.

Von Wright, G. H. (1951). An Essay on Modal Logic. Amsterdam: North-Holland.

Von Wright, G. H. (1963). The Varieties of Goodness. London: Routledge \& Keagan.

Von Wright, G. H. (1974). Causality and Determinism. Woodbridge Lecture (October and November of 1972). 
Von Wright, G. H. (1976). Determinism and the Study of Man. In J. Manninen, \& R. Tuomela (Eds.), Essays on Explanation and Understanding (pp. 415-435). Dordrecht: Reidel Publishing. http://dx.doi.org/10.1007/978-94-010-1823-4_18

Von Wright, G. H. (1984). Of Human Freedom. The Tanner Lectures of Human Values.

Weatherford, R. C. (2005). Determinism. In T. Honderich (Ed.), The Oxford Companion to Philosophy (pp. 194-196). Oxford: Oxford University Press.

Wolf, S. (1981). The Importance of Free Will. Mind, 90, 386-405. 